\title{
大変形を伴う柔軟マルチボディシステムのスライディングジョイント拘束*
}

\author{
山下 拓希 ${ }^{* 1}$, 杉山 博之*2
}

\section{Sliding Joint Constraints for the Large Deformation Analysis of Multibody Systems}

\author{
Hiroki YAMASHITA and Hiroyuki SUGIYAMA*2 \\ ${ }^{* 2}$ Department of Mechanical Engineering, Tokyo University of Science \\ Kudankita 1-14-6, Chiyoda-Ku, Tokyo, 102-0073 Japan
}

In this investigation, a numerical procedure that can be effectively used for modeling sliding joint constraints for the absolute nodal coordinate formulation is developed. To this end, the arc-length coordinates are introduced to define the time-variant location of the constraint definition point on flexible bodies, while the intermediate coordinates are introduced to derive a mapping between the generalized gradient coordinates and the rotational coordinates. With this mapping, sliding joint constraints can be efficiently formulated for a flexible body modeled using the absolute nodal coordinate formulation. Furthermore, existing constraint libraries formulated for rigid bodies can be employed for the absolute nodal coordinate formulation without modifications. It is also demonstrated that the arc-length coordinates and intermediate coordinates used for formulating sliding joint constraints can be systematically eliminated from the equations of motion and standard differential algebraic equations used for general multibody dynamics computer algorithms can be obtained.

Key Words : Multibody Dynamics, Simulation, Modeling, Joint Constraints, Large Deformation, Absolute Nodal Coordinate Formulation, Intermediate Coordinates

\section{1. 緒言}

近年，マルチボディダイナミクス解析における非線形有限要素法との連成問題，つまり，剛体と大変形を伴う 弾性体がジョイント拘束を介して連成した多体拘束系動力学問題に対寸る効率的な定式化手法の開発が活発に行 われている(1). 特に，マルチボディダイナミクスの数值計算アルゴリズムで用いられる非増分型解法に適した非 線形有限要素法として Absolute nodal coordinate formulation が提案されており, 種々の柔軟マルチボディシステム の動力学解析に適用されている(2). 本手法では, 既存の梁や板/シェルなどの構造要素に対してオイラー角やオ イラーパラメータなどの 3 次元回転変数を用いず，要素座標に関して定義された変位勾配をその節点座標として 用いることにより，要素の剛体回転および弾性変形を表し，大回転運動と弾性変形の複雑な連成を導くことなく 運動方程式を導くことができる特徵がある. その結果, 一般化質量行列が時間的に一定となり, 拘束系の動力学 問題を取り扱う上で問題となる非線形慣性力項の取扱いが容易となる.

しかしながら, Absolute nodal coordinate formulation では物体の 3 次元姿勢を表すために回転変数を用いないた め, 剛体とのジョイント拘束を定式化する際には, 要素の変位勾配座標によって定義されるジョイント座標系を 導入することによって定式化が行われてきた ${ }^{(2)}$ ，変位勾配ベクトルによって記述されるジョイント座標系を用い た定式化では，2物体間のジョイント座標系間で拘束関係を規定するため，回転運動や並進運動に関する自由度 は拘束されるが，拘束定義点における弾性体の断面変形が拘束されないという問題がある. さらに，ジョイント 座標系の姿勢行列が変位勾配ベクトルの非線形関数で表されるため, 拘束方程式が煩雑になり, 計算効率が損な われることがある．また，マルチボディダイナミクスの汎用プログラムに Absolute nodal coordinate formulation を 実装するためには，各種ジョイント拘束に対して拘束方程式やそのヤコビ行列を一般化節点座標に対して新たに 定式化する必要がある，そこで本研究では，Absolute nodal coordinate formulationによってモデル化された大変形

\footnotetext{
* 原稿受付 2010 年 11 月 11 日

*1 東京理科大学大学院（干102-0073 東京都千代田区九段北 1-14-6)

${ }^{* 2}$ 正員, 東京理科大学工学部（干102-0073 東京都千代田区九段北 1-14-6）

E-mail: sugiyama@rs.tus.ac.jp
} 
弾性体と剛体とのスライディングジョイント拘束を効率的にモデル化するために，著者らによって提案された中 間座標の概念 ${ }^{(3)}$ を柔軟多体系に対するスライディングジョイントに導入した定式化手法および数值計算アルゴリ ズムを提案する.

\section{Absolute Nodal Coordinate Formulation}

図 1 に示すように, Absolute nodal coordinate formulationの 3 次元梁要素では, 絶対座標系から見た梁の任意点 位置は次式によって表される ${ }^{(1)}$.

$$
\mathbf{r}^{i}=\mathbf{S}\left(\overline{\mathbf{x}}^{i}\right) \mathbf{e}^{i}
$$

ここで, $\mathbf{S}^{i}\left(\overline{\mathbf{x}}^{i}\right)$ は形状関数行列, $\overline{\mathbf{x}}^{i}=\left[\begin{array}{lll}x^{i} & y^{i} & z^{i}\end{array}\right]^{T}$ は要素座標ベクトル, $\mathbf{e}^{i}$ は要素 $i$ の節点座標ベクトルである. 要素 $i$ における節点 $k$ の節点座標ベクトル $\mathbf{e}^{i k}$ は次式で与えられる.

$$
\mathbf{e}^{i k}=\left[\left(\mathbf{r}^{i k}\right)^{T}\left(\frac{\partial \mathbf{r}^{i k}}{\partial x^{i}}\right)^{T}\left(\frac{\partial \mathbf{r}^{i k}}{\partial y^{i}}\right)^{T}\left(\frac{\partial \mathbf{r}^{i k}}{\partial z^{i}}\right)^{T}\right]^{T}
$$

ここで， $\mathbf{r}^{i k}$ は絶対座標系から見た節点 $k$ の位置を表し， $\partial \mathbf{r}^{i k} / \partial x^{i} ， \partial \mathbf{r}^{i k} / \partial y^{i}$ および $\partial \mathbf{r}^{i k} / \partial z^{i}$ は $x, y$ および $z$ 方向 の変位勾配べクトルである. 式(1)で与えられる位置ベクトルは次式のように記述することができる.

$$
\mathbf{r}^{i}=\mathbf{r}_{c}^{i}+y^{i} \frac{\partial \mathbf{r}_{c}^{i}}{\partial y^{i}}+z^{i} \frac{\partial \mathbf{r}_{c}^{i}}{\partial z^{i}}
$$

ここで， $\mathbf{r}_{c}^{i}$ は絶対座標系から見た梁の軸線上の任意点位置を表すべクトル， $\partial \mathbf{r}_{c}^{i} / \partial y^{i}$ と $\partial \mathbf{r}_{c}^{i} / \partial z^{i}$ は断面方向の変位 勾配ベクトルであり，それぞれ次式で表される ${ }^{(4)}$.

$$
\mathbf{r}_{c}^{i}=\mathbf{S}_{\mathrm{I}}^{i}\left(x^{i}\right) \mathbf{e}^{i}, \quad \frac{\partial \mathbf{r}_{c}^{i}}{\partial y^{i}}=\mathbf{S}_{\mathrm{II}}^{i}\left(x^{i}\right) \mathbf{e}^{i}, \quad \frac{\partial \mathbf{r}_{c}^{i}}{\partial z^{i}}=\mathbf{S}_{\mathrm{III}}^{i}\left(x^{i}\right) \mathbf{e}^{i}
$$

ここで，式(1)および(3)から $\mathbf{S}^{i}=\mathbf{S}_{\mathrm{I}}^{i}+y^{i} \mathbf{S}_{\mathrm{II}}^{i}+z^{i} \mathbf{S}_{\mathrm{III}}^{i}$ が成立する. 梁の軸線上の任意点の位置は $x^{i}$ に関して 3 次の Hermite 多項式を用いて $\mathbf{r}_{c}^{i}=\mathbf{S}_{\mathrm{I}}^{i}\left(x^{i}\right) \mathbf{e}^{i}$ と表される。 また, 断面の姿勢および変形は $x^{i}$ に関する線形補間から

Deformed configuration

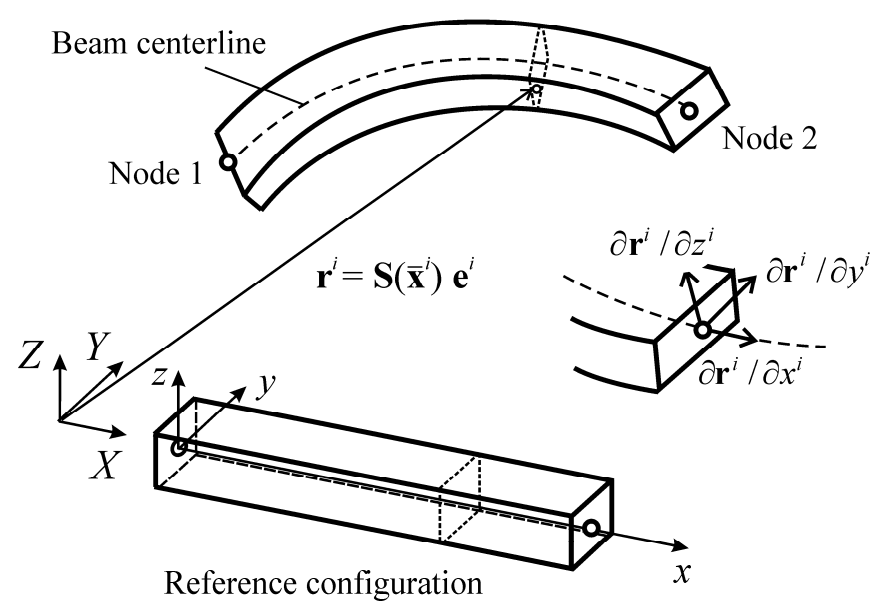

Fig.1 Beam element of the absolute nodal coordinate formulation 
$\partial \mathbf{r}_{c}^{i} / \partial y^{i}=\mathbf{S}_{\mathrm{II}}^{i}\left(x^{i}\right) \mathbf{e}^{i}$ および $\partial \mathbf{r}_{c}^{i} / \partial z^{i}=\mathbf{S}_{\mathrm{III}}^{i}\left(x^{i}\right) \mathbf{e}^{i}$ となる.

\section{3. 既往のジョイント拘束の定式化 ${ }^{(2)}$}

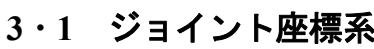

マルチボディダイナミクスでは, 回転ジョイント, シリンドリカルジョイント，ユニバーサルジョイントなど の多くのジョイント拘束は次式で表される基本拘束式の組み合わせにより定式化することができる(1).

$$
\mathbf{C}_{S}=\mathbf{r}^{i}-\mathbf{r}^{j}=\mathbf{0}, \quad C_{N 1}=\mathbf{v}^{i} \cdot \mathbf{v}^{j}=0, \quad C_{N 2}=\mathbf{v}^{i} \cdot\left(\mathbf{r}^{i}-\mathbf{r}^{j}\right)=0
$$

上式はそれぞれ，相対変位条件，直交条件，同軸条件を表す，2物体間の運動を拘束するためには，各物体にジ ヨイント座標系を定義し，その座標系に関して式(5)で表される拘束条件式を定義することになる．そのため， Absolute nodal coordinate formulation でモデル化された弾性体上でジョイント座標系を定義する必要がある．しか しながら, Absolute nodal coordinate formulation では，変位勾配ベクトルを用いて弾性体の回転と変形をパラメー タ化しているため，その変位勾配テンソルは正規直交行列にはならない，そのため，変位勾配ベクトルから姿勢 行列を新たに定義する必要がある. そこで, 次式のようなジョイント座標系が提案されている(2).

$$
\mathbf{A}_{t}^{i k}\left(\mathbf{e}^{i k}\right)=\left[\begin{array}{lll}
\mathbf{i}_{t}^{i k} & \mathbf{j}_{t}^{i k} & \mathbf{k}_{t}^{i k}
\end{array}\right]
$$

ここで，姿勢行列の成分は $x$ および $y$ 方向の変位勾配ベクトルを用いて次式のように表せる.

$$
\mathbf{i}_{t}^{i k}=\partial \hat{\mathbf{r}}^{i k} / \partial x^{i}, \quad \mathbf{j}_{t}^{i k}=\mathbf{k}_{t}^{i k} \times \mathbf{i}_{t}^{i k}, \quad \mathbf{k}_{t}^{i k}=\frac{\partial \hat{\mathbf{r}}^{i k} / \partial x^{i} \times \partial \hat{\mathbf{r}}^{i k} / \partial y^{i}}{\left|\partial \hat{\mathbf{r}}^{i k} / \partial x^{i} \times \partial \hat{\mathbf{r}}^{i k} / \partial y^{i}\right|}
$$

ただし， $\partial \hat{\mathbf{r}}^{i k} / \partial x^{i}$ および $\partial \hat{\mathbf{r}}^{i k} / \partial y^{i}$ はそれぞれ $\partial \mathbf{r}^{i k} / \partial x^{i}$ と $\partial \mathbf{r}^{i k} / \partial x^{i}$ の単位ベクトルである.このような座標系は Tangent frame と呼ばれ，その $X$ 軸は梁の軸線の接ベクトルの方向と一致する.

\section{$3 \cdot 2$ スライディングジョイント拘束}

弾性体に対する並進ジョイントでは拘束定義点が弾性体上を移動し，その位置が時間および弾性体の変形に依 存するため, 動的な移動境界問題を厳密に解く必要がある. 一方, Absolute nodal coordinate formulation では構造 要素の絶対位置ベクトルが式(1)のように極めてシンプルに記述できるため, 軸線に沿った要素座標 $x^{i}=s^{i}$ をスラ イディングジョイントの拘束定義点を表す弧長変数として定義した定式化が提案されている ${ }^{(2)}$. 本定式化では, 図 2 に示寸ような, 弾性体 $i$ が剛体 $j$ とシリンドリカルジョイントによって結合されている場合, 拘束方程式は 次式で与えられる.

$$
\mathbf{C}\left(\mathbf{e}^{i}, s^{i}, \mathbf{q}^{j}\right)=\left[\begin{array}{c}
\mathbf{r}^{i}-\mathbf{r}^{j} \\
\partial \mathbf{r}^{i} / \partial x^{i} \cdot \mathbf{v}_{1}^{j} \\
\partial \mathbf{r}^{i} / \partial x^{i} \cdot \mathbf{v}_{2}^{j}
\end{array}\right]
$$

ここで, $\mathbf{r}^{i}$ は弾性体 $i$ の拘束定義点の位置ベクトルであり, 要素節点座標 $\mathbf{e}^{i}$ だけでなく, 軸線に沿った弧長変数 $s^{i}$ の関数として $\mathbf{r}^{i}=\mathbf{S}\left(s^{i}\right) \mathbf{e}^{i}$ と与えられ, $\partial \mathbf{r}^{i} / \partial x^{i}$ はその位置における軸線方向の変位勾配ベクトルである. また, $\mathbf{r}^{j}$ は剛体 $j$ 上の拘束定義点を表す位置ベクトルであり, $\mathbf{v}_{1}^{j}$ および $\mathbf{v}_{2}^{j}$ は剛体がスライドしていくジョイント軸の方向 を表すべクトル $\mathbf{v}^{j}$ と直交する 2 つのベクトルである.つまり， $\partial \mathbf{r}^{i} / \partial x^{i}$ と $\mathbf{v}^{j}$ は互いに平行であることが保証され，

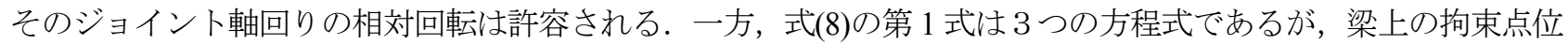
置を規定する座標 $s^{i}$ は変数であるため, 軸線方向の相対運動は拘束されず, それと直交する 2 方向の相対並進自 由度のみが拘束されることに注意が必要である. その結果, 拘束方程式の数は 5 つであるが, 拘束される相対自 


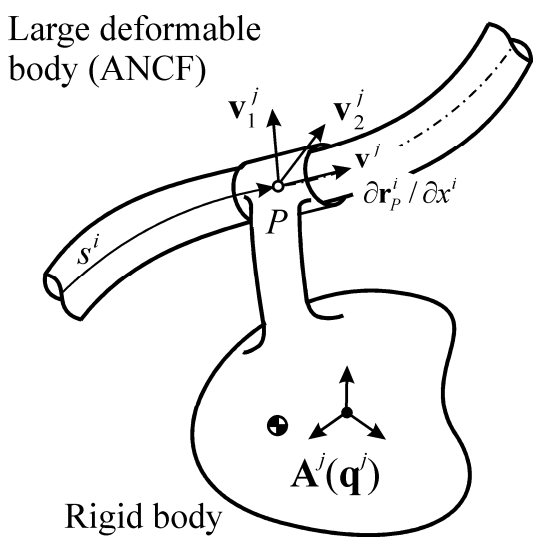

Fig.2 Cylindrical joint for the absolute nodal coordinate formulation

由度は 4 となる。つまり, ジョイント軸方向の相対並進 1 自由度とその軸回り相対回転 1 自由度が許容されるこ とになる。

スライディングジョイントを含む弾性体と剛体の拘束条件付の変分運動方程式は次式のように導出できる(2).

$$
\left.\begin{array}{l}
\delta \mathbf{q}^{T}\left(\mathbf{M}_{r r} \ddot{\mathbf{q}}+\mathbf{C}_{\mathbf{q}}^{T} \boldsymbol{\lambda}-\mathbf{Q}_{r}\right)+\delta \mathbf{e}^{T}\left(\mathbf{M}_{a a} \ddot{\mathbf{e}}+\mathbf{C}_{\mathbf{e}}^{T} \boldsymbol{\lambda}-\mathbf{Q}_{a}\right)+\delta \mathbf{s}^{T} \mathbf{C}_{\mathbf{s}}^{T} \boldsymbol{\lambda}=0 \\
\mathbf{C}(\mathbf{q}, \mathbf{e}, \mathbf{s})=\mathbf{0}
\end{array}\right\}
$$

ここで， $\mathbf{q}$ は剛体の一般化座標， $\mathbf{M}_{a a}$ と $\mathbf{M}_{r r}$ はそれぞれ弾性体および岡体の質量行列である．一方， $\mathbf{Q}_{a}$ と $\mathbf{Q}_{r}$ は

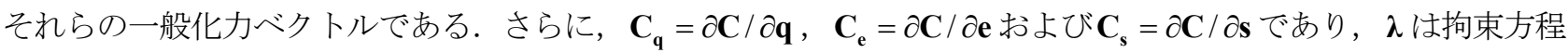
式 $\mathbf{C}(\mathbf{q}, \mathbf{e}, \mathbf{s})=\mathbf{0}$ に対するラグランジェ未定乗数である. また, 弧長座標 $\mathbf{s}$ が導入されたことにより $\mathbf{C}_{\mathbf{s}}^{T} \lambda=\mathbf{0}$ が得ら れ，全てのラグランジェ未定乗数は独立ではないことが分かる．これは，軸線方向の相対運動は拘束されないた め, ジョイント軸に沿った方向の拘束力はゼロになることを意味する.

\section{4. 中間座標を用いたジョイント拘束の定式化}

\section{$4 \cdot 1$ 中間座標を用いたスライディングジョイントの定式化}

3 章で示したように，変位勾配ベクトルで定義されたジョイント拘束式の定式では, Absolute nodal coordinate formulation に対する全てのジョイント拘束に対して拘束方程式の再定式化が必要となる. そこで，これらの問題 を解決するため, 図 3 に示すような, 中間座標を用いた Absolute nodal coordinate formulation に対するスライディ ングジョイント拘束の定式化を提案する．剛体とのジョイント拘束を定義するために，変位勾配ベクトルで定義 されたジョイント座標系を用いず，剛体と同じ6つの変数により構成される中間座標を導入することにより，剛 体に対する既存のジョイント拘束モジュールをそのまま利用して弾性体と剛体間のジョイント拘束の定式化を行 う.つまり, Absolute nodal coordinate formulation でモデル化された弾性体の拘束定義点において，新たに中間座 標 $\mathbf{p}^{i}$ を導入し， $\mathbf{p}^{i}$ にって定義されたジョイント座標系を中間座標系と定義することにより，中間座標系を用い て剛体とのジョイント拘束を定義する，そこで，中間座標 $\mathbf{p}^{i}$ を次式のように定義する ${ }^{(3)}$.

$$
\mathbf{p}^{i}=\left[\begin{array}{ll}
\mathbf{R}_{p}^{i^{T}} & \boldsymbol{\theta}_{p}^{i^{T}}
\end{array}\right]^{T}
$$

ここで， $\mathbf{R}_{p}^{i}$ は位置ベクトル， $\mathbf{\theta}_{p}^{i}$ はオイラー角やオイラーパラメータなどの回転変数であり，その姿勢行列は次 式で与えられる. 


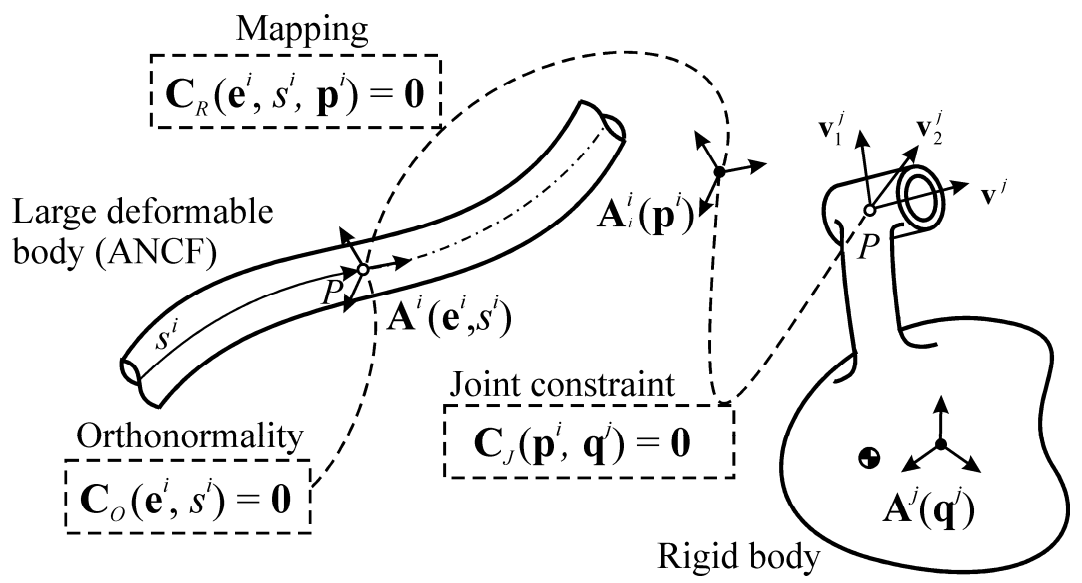

Fig.3 Cylindrical joint using intermediate coordinates

$$
\mathbf{A}_{i}^{i}\left(\boldsymbol{\theta}_{p}^{i}\right)=\left[\begin{array}{lll}
\mathbf{i}_{i}^{i} & \mathbf{j}_{i}^{i} & \mathbf{k}_{i}^{i}
\end{array}\right]
$$

また，中間座標は，弧長座標 $\mathbf{s}$ と同様，それに対応する質量や力が存在しないスラック変数であり，弾性体や岡 体の一般化座標と異なる扱いが必要であることに注意を要する(5).

以上から，中間座標 $\mathbf{p}^{i}$ と剛体 $j$ の一般化座標 $\mathbf{q}^{j}$ を用いれば，既存の剛体間のジョイント拘束ライブラリを用い て，図 3 に示すシリンドリカルジョイントの拘束方程式は次式で与えられる.

$$
\mathbf{C}_{J}\left(\mathbf{p}^{i}, \mathbf{q}^{j}\right)=\left[\begin{array}{c}
\mathbf{R}_{p}^{i}-\mathbf{r}^{j} \\
\mathbf{i}_{i}^{i} \cdot \mathbf{v}_{1}^{j} \\
\mathbf{i}_{i}^{i} \cdot \mathbf{v}_{2}^{j}
\end{array}\right] \text { または } \quad \mathbf{C}_{J}\left(\mathbf{p}^{i}, \mathbf{q}^{j}\right)=\left[\begin{array}{c}
\left(\mathbf{A}_{i}^{i}\right)^{T}\left(\mathbf{R}_{p}^{i}-\mathbf{r}^{j}\right) \\
\mathbf{i}_{i}^{i} \cdot \mathbf{v}_{1}^{j} \\
\mathbf{i}_{i}^{i} \cdot \mathbf{v}_{2}^{j}
\end{array}\right]
$$

上式は式(5)で与えられる基本拘束式より構成されるため，剛体に対するジョイント拘束ライブラリをそのまま利 用して定式化が可能である。これは，中間座標と剛体の座標間では，シリンドリカルジョイントのジョイント軸 を回転軸とした回転ジョイントを定義したことに相当し，ジョイント軸に沿った位置の変化は弾性体の弧長変数 $s^{i}$ で決定される。つまり，式(12)にジョイント軸回りの回転を拘束する姿勢拘束条件を 1 式追加すれば，プリズ マティックジョイントを定式化することが出来る.

図 3 に示すように, 中間座標系は剛体とのジョイント拘束だけでなく, 弾性体の拘束定義点における節点座標 とその位置および姿勢を共有する。つまり, 中間座標と一般化節点座標のマッピングが必要になる. ジョイント 拘束が定義される位置では, 弾性体の断面変形が拘束されると仮定し, 拘束定義点における变位勾配ベクトルの 正規直交条件から新たに次式を定義する.

$$
\mathbf{C}_{O}\left(\mathbf{e}^{i}, s^{i}\right)=\left[\begin{array}{c}
\partial \mathbf{r}^{i} / \partial x^{i} \cdot \partial \mathbf{r}^{i} / \partial x^{i}-1 \\
\partial \mathbf{r}^{i} / \partial y^{i} \cdot \partial \mathbf{r}^{i} / \partial y^{i}-1 \\
\partial \mathbf{r}^{i} / \partial z^{i} \cdot \partial \mathbf{r}^{i} / \partial z^{i}-1 \\
\partial \mathbf{r}^{i} / \partial x^{i} \cdot \partial \mathbf{r}^{i} / \partial y^{i} \\
\partial \mathbf{r}^{i} / \partial x^{i} \cdot \partial \mathbf{r}^{i} / \partial z^{i} \\
\partial \mathbf{r}^{i} / \partial y^{i} \cdot \partial \mathbf{r}^{i} / \partial z^{i}
\end{array}\right]=\mathbf{0}
$$

本条件を導入することにより，変位勾配の極分解定理から，拘束定義点におけるストレッチテンソルが単位行列 になるため, 弾性体上の拘束定義点における姿勢行列は次式のように簡便に記述することができる. 


$$
\mathbf{A}^{i}\left(\mathbf{e}^{i}, s^{i}\right)=\left[\begin{array}{lll}
\frac{\partial \mathbf{r}^{i}}{\partial x^{i}} & \frac{\partial \mathbf{r}^{i}}{\partial y^{i}} & \frac{\partial \mathbf{r}^{i}}{\partial z^{i}}
\end{array}\right]
$$

ここで， $\mathbf{r}^{i}=\mathbf{S}\left(s^{i}\right) \mathbf{e}^{i}$ である．また，この姿勢行列を用いれば，拘束定義点の一般化節点ベクトル $\mathbf{e}^{i}$ と中間座標 $\mathbf{p}^{i}$ との間のマッピング方程式は次式で与えられる.

$$
\mathbf{C}_{R}\left(\mathbf{e}^{i}, s^{i}, \mathbf{p}^{i}\right)=\left[\begin{array}{c}
\mathbf{r}^{i}-\mathbf{R}_{p}^{i} \\
\partial \mathbf{r}^{i} / \partial x^{i} \cdot \mathbf{j}_{i}^{i} \\
\partial \mathbf{r}^{i} / \partial x^{i} \cdot \mathbf{k}_{i}^{i} \\
\partial \mathbf{r}^{i} / \partial y^{i} \cdot \mathbf{k}_{i}^{i}
\end{array}\right]=\mathbf{0}
$$

以上から，中間座標を導入することにより以下の 3 組の拘束方程式でスライディングジョイント拘束を定式化す ることができる.

$$
\mathbf{C}\left(\mathbf{e}^{i}, s^{i}, \mathbf{p}^{i}, \mathbf{q}^{j}\right)=\left[\begin{array}{c}
\mathbf{C}_{O}\left(\mathbf{e}^{i}, s^{i}\right) \\
\mathbf{C}_{J}\left(\mathbf{p}^{i}, \mathbf{q}^{j}\right) \\
\mathbf{C}_{R}\left(\mathbf{e}^{i}, s^{i}, \mathbf{p}^{i}\right)
\end{array}\right]=\mathbf{0}
$$

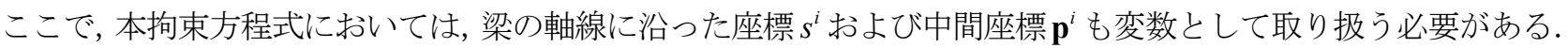
仮想仕事の原理より，中間座標を用いたスライディングジョイント拘束を含むマルチボディシステムの変分運動 方程式は次式で表される.

$$
\left.\begin{array}{l}
\delta \mathbf{q}^{T}\left(\mathbf{M}_{r r} \ddot{\mathbf{q}}+\mathbf{C}_{\mathbf{q}}^{T} \boldsymbol{\lambda}-\mathbf{Q}_{r}\right)+\delta \mathbf{e}^{T}\left(\mathbf{M}_{a a} \ddot{\mathbf{e}}+\mathbf{C}_{\mathbf{e}}^{T} \boldsymbol{\lambda}-\mathbf{Q}_{a}\right)+\delta \mathbf{p}^{T} \mathbf{C}_{\mathbf{p}}^{T} \boldsymbol{\lambda}+\delta \mathbf{s}^{T} \mathbf{C}_{\mathbf{s}}^{T} \boldsymbol{\lambda}=0 \\
\mathbf{C}(\mathbf{q}, \mathbf{e}, \mathbf{p}, \mathbf{s})=\mathbf{0}
\end{array}\right\}
$$

加速度レベルの拘束方程式を用いれば，式(17)は次式のようにまとめることができる.

$$
\begin{aligned}
& \mathbf{M}_{r r} \ddot{\mathbf{q}}+\mathbf{C}_{\mathbf{q}}^{T} \boldsymbol{\lambda}=\mathbf{Q}_{r} \\
& \mathbf{M}_{a a} \ddot{\mathbf{e}}+\mathbf{C}_{\mathbf{e}}^{T} \boldsymbol{\lambda}=\mathbf{Q}_{a} \\
& \mathbf{C}_{\mathbf{s}}^{T} \boldsymbol{\lambda}=\mathbf{0} \\
& \mathbf{C}_{\mathbf{p}}^{T} \boldsymbol{\lambda}=\mathbf{0} \\
& \mathbf{C}_{\mathbf{q}} \ddot{\mathbf{q}}+\mathbf{C}_{\mathbf{e}} \ddot{\mathbf{e}}+\mathbf{C}_{\mathbf{s}} \ddot{\mathbf{s}}+\mathbf{C}_{\mathbf{p}} \ddot{\mathbf{p}}=\mathbf{Q}_{d}
\end{aligned}
$$

ここで, $\mathbf{C}_{\mathbf{s}}^{T} \boldsymbol{\lambda}=\mathbf{0}$ および $\mathbf{C}_{\mathrm{p}}^{T} \boldsymbol{\lambda}=\mathbf{0}$ はすべてのラグランジェ未定乗数が独立ではないことを意味する. 例えば， Absolute nodal coordinate formulation でモデル化された弾性体と岡体がシリンドリカルジョイントで結合された場 合, 回転ジョイントに対する既存の拘束方程式が $5 つ$, 正規直交化条件 $\left(\mathbf{C}_{O}\left(\mathbf{e}^{i}, s^{i}\right)=\mathbf{0}\right)$ が 6 つ, 変位勾配変数 と中間座標間のマッピング方程式 $\left(\mathbf{C}_{R}\left(\mathbf{e}^{i}, s^{i}, \mathbf{p}^{i}\right)=\mathbf{0}\right)$ が 6 つ必要となり, 計 17 個の拘束方程式が導出される. 一方，拘束定義点における弾性体（Absolute nodal coordinate formulation）の自由度は 12 ，スライディングジョイ ントの位置を規定する弧長変数 $s^{i}$ が 1 つ，中間座標が 6 つ，剛体の一般化座標は 6 つであるため，計 25 個の変 数に対して， 8 自由度が残る. 6 自由度はベースボディの並進 3 自由度，回転 3 自由度に相当するため，残りの 2 自由度で梁の軸線に沿った相対並進 1 自由度およびジョイント軸回りの相対回転 1 自由度が表されていること が分かる. 以上から，本モデル化により，正しく大変形弾性体と岡体間のスライディングジョイント拘束が定式 化可能であることが分かる.

提案手法では，中間座標の導入により取り扱う変数の数は増えるが，変位勾配ベクトルに対する正規直交条件 により，ジョイント座標系の姿勢行列が簡単に表され，その結果，中間座標とのマッピング方程式がシンプルに 
なるだけでなく，剛体に対して確立された種々のジョイント拘束ライブラリをそのまま Absolute nodal coordinate formulation に適用できるため, 汎用性に優れた手法であると考えられる. また, Absolute nodal coordinate formulation でモデル化された弾性体間のジョイント拘束に対しても, それぞれの弾性体の拘束定義点に中間座標系を定義し, 中間座標と節点座標のマッピング方程式および正規直交条件を導入することで，定式化可能である.

\section{$4 \cdot 2$ 拘束定義点が固定された場合の運動方程式}

スラック変数として定義した中間座標 $\mathbf{p}^{i}$ を用いて, スライディングジョイントを含むジョイント拘束の定式化 手法を示した。一方，本手法は拘束定義点が物体上を移動しない回転ジョイントや剛結合ジョイントに対しても 適用することができる，つまり，梁の軸線沿った弧長変数 $s^{i}$ がある拘束定義点で固定されれば，弧長変数 $s^{i}$ は変 数ではなくなるため, 式(17)は次式のように記述できる.

$$
\left.\begin{array}{l}
\delta \mathbf{q}^{T}\left(\mathbf{M}_{r r} \ddot{\mathbf{q}}+\mathbf{C}_{\mathbf{q}}^{T} \boldsymbol{\lambda}-\mathbf{Q}_{r}\right)+\delta \mathbf{e}^{T}\left(\mathbf{M}_{a a} \ddot{\mathbf{e}}+\mathbf{C}_{\mathbf{e}}^{T} \boldsymbol{\lambda}-\mathbf{Q}_{a}\right)+\delta \mathbf{p}^{T} \mathbf{C}_{\mathbf{p}}^{T} \boldsymbol{\lambda}=0 \\
\mathbf{C}(\mathbf{q}, \mathbf{e}, \mathbf{p})=\mathbf{0}
\end{array}\right\}
$$

さらに，拘束方程式の加速度レベルを用いれば，次式のようにまとめることができる(3).

$$
\left.\begin{array}{l}
\mathbf{M}_{r r} \ddot{\mathbf{q}}+\mathbf{C}_{\mathbf{q}}^{T} \boldsymbol{\lambda}=\mathbf{Q}_{r} \\
\mathbf{M}_{a a} \ddot{\mathbf{e}}+\mathbf{C}_{\mathbf{e}}^{T} \boldsymbol{\lambda}=\mathbf{Q}_{a} \\
\mathbf{C}_{\mathbf{p}}^{T} \boldsymbol{\lambda}=\mathbf{0} \\
\mathbf{C}_{\mathbf{q}} \ddot{\mathbf{q}}+\mathbf{C}_{\mathbf{e}} \ddot{\mathbf{e}}+\mathbf{C}_{\mathbf{p}} \ddot{\mathbf{p}}=\mathbf{Q}_{d}
\end{array}\right\}
$$

\section{5. 中間座標および弧長変数を消去した運動方程式}

4 章では，スライディングジョイント拘束を含む柔軟マルチボディシステムに対して，中間座標を用いたジョ イント拘束の定式化手法を提案した. しかし，中間座標を導入したことにより変数の数が増え，式(18)のような 大規模な微分代数方程式が導かれるという問題がある. そこで，本章では運動方程式中から弧長変数 $\mathbf{s}$ および中 間座標 $\mathbf{p}$ をシステマティックに消去する方法を示す．そこで， $\mathbf{C}_{\mathrm{s}}^{T} \boldsymbol{\lambda}=\mathbf{0}$ および $\mathbf{C}_{\mathrm{p}}^{T} \boldsymbol{\lambda}=\mathbf{0}$ より，すべてのラグランジ エ未定乗数が独立でないことが分かるため, 式(16)の拘束方程式を独立および従属な拘束方程式に分割する. こ こで，独立および従属とは，各拘束方程式に対するラグランジェ未定乗数が独立か従属かを表している．すなわ ち,

$$
\mathbf{C}(\mathbf{e}, \mathbf{q}, \mathbf{s}, \mathbf{p})=\left[\begin{array}{l}
\Phi(\mathbf{e}, \mathbf{q}, \mathbf{s}, \mathbf{p}) \\
\Psi(\mathbf{e}, \mathbf{s}, \mathbf{p})
\end{array}\right]=\mathbf{0}
$$

なお，

$$
\boldsymbol{\Phi}(\mathbf{e}, \mathbf{q}, \mathbf{s}, \mathbf{p})=\left[\begin{array}{c}
\mathbf{C}_{O}(\mathbf{e}, \mathbf{s}) \\
\mathbf{C}_{J}^{n}(\mathbf{p}, \mathbf{q})
\end{array}\right], \quad \boldsymbol{\Psi}(\mathbf{e}, \mathbf{q}, \mathbf{s}, \mathbf{p})=\left[\begin{array}{l}
\boldsymbol{\Psi}_{1} \\
\boldsymbol{\Psi}_{2}
\end{array}\right]=\left[\begin{array}{l}
\mathbf{C}_{J}^{d}(\mathbf{p}, \mathbf{q}) \\
\mathbf{C}_{R}(\mathbf{e}, \mathbf{s}, \mathbf{p})
\end{array}\right]
$$

ここで, 式(22)の $\mathbf{C}_{J}^{d}(\mathbf{p}, \mathbf{q})$ は式(12)で与えられるスライディングジョイントの拘束方程式 $\mathbf{C}_{J}(\mathbf{p}, \mathbf{q})=\mathbf{0}$ のうち, 梁 の軸線方向の拘束成分 $\mathbf{C}_{J}^{d}(\mathbf{p}, \mathbf{q})=\left(\mathbf{i}_{i}^{i}\right)^{T}\left(\mathbf{R}_{p}^{i}-\mathbf{r}_{P}^{j}\right)=0$ を表し, $\mathbf{C}_{J}^{n}(\mathbf{p}, \mathbf{q})=\mathbf{0}$ はそれ以外の拘束方程式である.つまり, $\mathbf{C}_{J}^{d}(\mathbf{p}, \mathbf{q})=0$ で表される方向には運動が拘束されないため, この拘束方程式に対する拘束力はゼロとなる. 一方, $\mathbf{C}_{J}^{n}(\mathbf{p}, \mathbf{q})=\mathbf{0}$ および正規直交条件 $\mathbf{C}_{O}\left(\mathbf{e}^{i}, \mathbf{s}^{i}\right)=\mathbf{0}$ による拘束力はゼロにならないため, これらを独立な拘束方程式 $\boldsymbol{\Phi}(\mathbf{e}, \mathbf{p}, \mathbf{q})=\mathbf{0}$ とする. また, $\mathbf{C}_{J}^{d}(\mathbf{p}, \mathbf{q})=0$ にマッピング方程式 $\boldsymbol{\Psi}_{2}=\mathbf{C}_{R}(\mathbf{e}, \mathbf{s}, \mathbf{p})=\mathbf{0}$ を加えた拘束方程式 $\boldsymbol{\Psi}(\mathbf{e}, \mathbf{q}, \mathbf{s}, \mathbf{p})=\mathbf{0}$ を従属な拘束方程式と定義する. 消去したい変数は変数 $\mathbf{p}$ および $\mathbf{s}$ であるため, まず $\boldsymbol{\Psi}_{2}(\mathbf{e}, \mathbf{s}, \mathbf{p})=\mathbf{0}$ の時間微分から次式を得ることができる. 


$$
\dot{\mathbf{p}}=\mathbf{B}_{R 1} \dot{\mathbf{e}}+\mathbf{B}_{R 2} \dot{\mathbf{s}}, \quad \ddot{\mathbf{p}}=\mathbf{B}_{R 1} \ddot{\mathbf{e}}+\mathbf{B}_{R 2} \ddot{\mathbf{s}}+\boldsymbol{\gamma}_{p}
$$

ここで, $\gamma_{p}$ は速度二乗で表される非線形項, $\mathbf{B}_{R 1}$ および $\mathbf{B}_{R 2}$ は速度変換行列であり, それぞれ次式で与えられる.

$$
\mathbf{B}_{R 1}=-\boldsymbol{\Psi}_{2 \mathbf{p}}^{-1} \boldsymbol{\Psi}_{2 \mathbf{e}}, \quad \mathbf{B}_{R 2}=-\boldsymbol{\Psi}_{2 \mathbf{p}}^{-1} \boldsymbol{\Psi}_{2 \mathbf{s}}
$$

ただし $, \quad \boldsymbol{\Psi}_{2 \mathbf{p}}=\partial \boldsymbol{\Psi}_{2} / \partial \mathbf{p}, \quad \boldsymbol{\Psi}_{2 \mathbf{e}}=\partial \boldsymbol{\Psi}_{2} / \partial \mathbf{e}$ および $\boldsymbol{\Psi}_{2 \mathbf{s}}=\partial \boldsymbol{\Psi}_{2} / \partial \mathbf{s}$ である. さらに, $\boldsymbol{\Psi}_{1}(\mathbf{p}, \mathbf{q})=\mathbf{0}$ の時間微分に式(23) の関係を用いて整理すれば, 次式が得られる.

$$
\dot{\mathbf{s}}=\mathbf{B}_{1} \dot{\mathbf{e}}+\mathbf{B}_{2} \dot{\mathbf{q}}, \quad \ddot{\mathbf{s}}=\mathbf{B}_{1} \ddot{\mathbf{e}}+\mathbf{B}_{2} \ddot{\mathbf{q}}+\boldsymbol{\gamma}_{s}
$$

ここで、 $\gamma_{s}$ は速度二乗で表わされる非線形項， $\mathbf{B}_{1}$ および $\mathbf{B}_{2}$ は速度変換行列でありそれぞれ，次式で与えられる.

$$
\mathbf{B}_{1}=-\left(\boldsymbol{\Psi}_{1 \mathbf{p}} \mathbf{B}_{R 2}\right)^{-1} \boldsymbol{\Psi}_{1 \mathbf{p}} \mathbf{B}_{R 1}, \quad \mathbf{B}_{2}=-\left(\boldsymbol{\Psi}_{1 \mathbf{p}} \mathbf{B}_{R 2}\right)^{-1} \boldsymbol{\Psi}_{1 \mathbf{q}}
$$

一方，式(22)を式(17)に代入すると，変分運動方程式は

$$
\begin{aligned}
& \delta \mathbf{q}^{T}\left(\mathbf{M}_{r r} \ddot{\mathbf{q}}+\boldsymbol{\Phi}_{\mathbf{q}}^{T} \boldsymbol{\lambda}_{\phi}+\boldsymbol{\Psi}_{\mathbf{q}}^{T} \boldsymbol{\lambda}_{\psi}-\mathbf{Q}_{r}\right)+\delta \mathbf{e}^{T}\left(\mathbf{M}_{a a} \ddot{\mathbf{e}}+\boldsymbol{\Phi}_{\mathrm{e}}^{T} \boldsymbol{\lambda}_{\phi}+\boldsymbol{\Psi}_{\mathrm{e}}^{T} \boldsymbol{\lambda}_{\psi}-\mathbf{Q}_{a}\right) \\
& +\delta \mathbf{p}^{T}\left(\boldsymbol{\Phi}_{\mathbf{p}}^{T} \boldsymbol{\lambda}_{\phi}+\boldsymbol{\Psi}_{\mathbf{p}}^{T} \boldsymbol{\lambda}_{\psi}\right)+\delta \mathbf{s}^{T}\left(\boldsymbol{\Phi}_{\mathbf{s}}^{T} \boldsymbol{\lambda}_{\phi}+\boldsymbol{\Psi}_{\mathbf{s}}^{T} \boldsymbol{\lambda}_{\psi}\right)=0
\end{aligned}
$$

と表される.ここで， $\lambda_{\phi}$ と $\lambda_{\psi}$ は $\boldsymbol{\Phi}(\mathbf{e}, \mathbf{p}, \mathbf{q})=\mathbf{0}$ および $\boldsymbol{\Psi}(\mathbf{e}, \mathbf{p})=\mathbf{0}$ に対するラグランジェ未定乗数である. そこで， 式(23)より求まる $\delta \mathbf{p}=\mathbf{B}_{R 1} \delta \mathbf{e}+\mathbf{B}_{R 2} \delta \mathbf{s}$ および式(25)より求まる $\delta \mathbf{s}=\mathbf{B}_{1} \delta \mathbf{e}+\mathbf{B}_{2} \delta \mathbf{q}$ なる関係を式(27)へ代入して整理 すれば,

$$
\begin{aligned}
& \delta \mathbf{q}^{T}\left(\mathbf{M}_{r r} \ddot{\mathbf{q}}+\left(\boldsymbol{\Phi}_{\mathbf{q}}+\boldsymbol{\Phi}_{\mathbf{s}} \mathbf{B}_{2}+\boldsymbol{\Phi}_{\mathbf{p}} \mathbf{B}_{R 2} \mathbf{B}_{2}\right)^{T} \boldsymbol{\lambda}_{\phi}-\mathbf{Q}_{r}\right) \\
& +\delta \mathbf{e}^{T}\left(\mathbf{M}_{a a} \ddot{\mathbf{e}}+\left(\boldsymbol{\Phi}_{\mathbf{e}}+\boldsymbol{\Phi}_{\mathbf{s}} \mathbf{B}_{1}+\boldsymbol{\Phi}_{\mathbf{p}}\left(\mathbf{B}_{R 1}+\mathbf{B}_{R 2} \mathbf{B}_{1}\right)\right)^{T} \boldsymbol{\lambda}_{\phi}-\mathbf{Q}_{a}\right)=0
\end{aligned}
$$

となり，剛体および弾性体の一般化座標 $\mathbf{q}$ およ゙ $\mathbf{e}$ のみに関する変分運動方程式が得られる.さらに，従属なラ グランジェ未定乗数 $\lambda_{\psi}$ が自動的に消去できることが分かる。これは，式(24)および式(26)で定義される速度変換 行列を用いれば次式が恒等的に成り立つためである.

$$
\left.\begin{array}{l}
\boldsymbol{\Psi}_{\mathbf{q}}+\boldsymbol{\Psi}_{\mathbf{s}} \mathbf{B}_{2}+\boldsymbol{\Psi}_{\mathbf{p}} \mathbf{B}_{R 2} \mathbf{B}_{2}=\mathbf{0} \\
\boldsymbol{\Psi}_{\mathbf{e}}+\boldsymbol{\Psi}_{\mathbf{s}} \mathbf{B}_{1}+\Psi_{\mathbf{p}}\left(B_{R 1}+B_{R 2} B_{1}\right)=\mathbf{0}
\end{array}\right\}
$$

さらに，独立な拘束方程式から求まる $\ddot{\mathbf{p}}=\mathbf{B}_{R 1} \ddot{\mathbf{e}}+\mathbf{B}_{R 2} \ddot{\mathbf{s}}+\boldsymbol{\gamma}_{p}$ および $\ddot{\mathbf{s}}=\mathbf{B}_{1} \ddot{\mathbf{e}}+\mathbf{B}_{2} \ddot{\mathbf{q}}+\boldsymbol{\gamma}_{s}$ なる関係を用いて加速度レべ ルの拘束方程式を整理すれば,

となる.ここで,

$$
\mathbf{H} \ddot{\mathbf{q}}+\mathbf{L} \ddot{\mathbf{e}}=\hat{\mathbf{Q}}_{d}
$$

$$
\left.\begin{array}{l}
\mathbf{H}=\boldsymbol{\Phi}_{\mathbf{q}}+\boldsymbol{\Phi}_{\mathbf{s}} \mathbf{B}_{2}+\boldsymbol{\Phi}_{\mathbf{p}} \mathbf{B}_{R 2} \mathbf{B}_{2} \\
\mathbf{L}=\boldsymbol{\Phi}_{\mathbf{e}}+\boldsymbol{\Phi}_{\mathbf{s}} \mathbf{B}_{1}+\boldsymbol{\Phi}_{\mathbf{p}}\left(\mathbf{B}_{R 1}+\mathbf{B}_{R 2} \mathbf{B}_{1}\right)
\end{array}\right\}
$$

以上から，中間座標 $\mathbf{p}$ およ゙弧長変数 $\mathbf{s}$ を運動方程式中からシステマティックに消去した運動方程式を次式のよ うに得ることができる。

$$
\left.\begin{array}{l}
\mathbf{M}_{r r} \ddot{\mathbf{q}}+\mathbf{H}^{T} \boldsymbol{\lambda}_{\phi}=\mathbf{Q}_{r} \\
\mathbf{M}_{a a} \ddot{\mathbf{e}}+\mathbf{L}^{T} \boldsymbol{\lambda}_{\phi}=\mathbf{Q}_{a} \\
\mathbf{H} \ddot{\mathbf{q}}+\mathbf{L} \ddot{\mathbf{e}}=\hat{\mathbf{Q}}_{d}
\end{array}\right\}
$$


ここで，式(32)は理論上，式(18)と等価な運動方程式であるが，中間座標 $\mathbf{p}$ おび弧長変数 $\mathbf{s}$ を消去した分だけ少 ない変数で運動方程式が記述できていることが分かる．また，式(32)のように中間座標を陽に含まない微分代数 方程式が導出できたことにより，既存の汎用マルチボディダイナミクスコードに本アルゴリズムをそのまま実装 可能である.

\section{6. 数値計算例}

\section{$6 \cdot 1$ 弾性ケーブルを滑り降りる弾性 2 重振子}

図 4 に示寸ように長さ $0.5 \mathrm{~m}$ の剛体および弾性体より構成される二重振子モデルを考える. 剛体リンクの一端

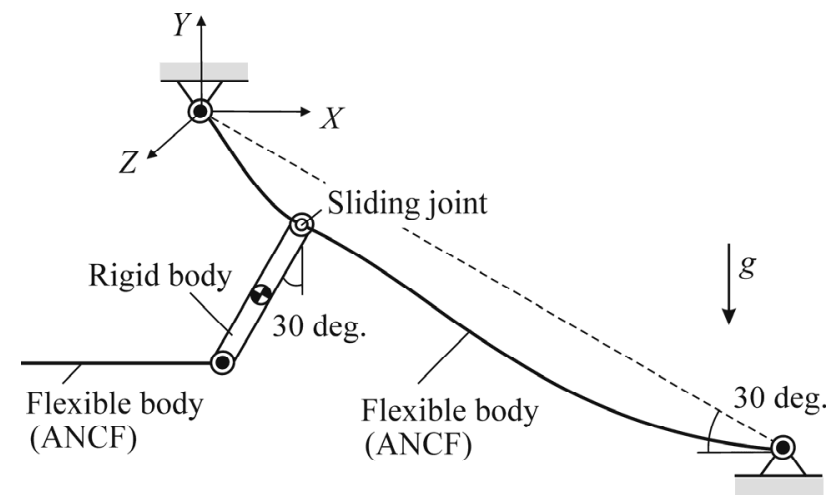

Fig.4 Flexible double pendulum subjected to sliding joint

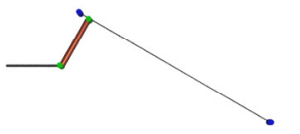

$t=0.1 \mathrm{~s}$

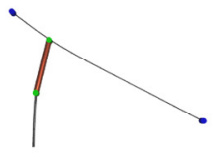

$t=0.6 \mathrm{~s}$

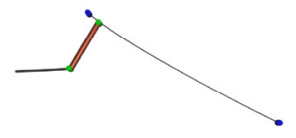

$t=0.2 \mathrm{~s}$

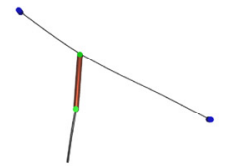

$t=0.7 \mathrm{~s}$

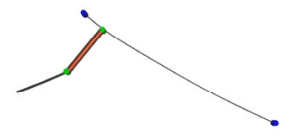

$t=0.3 \mathrm{~s}$

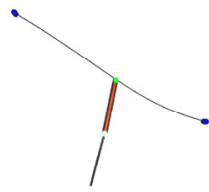

$t=0.8 \mathrm{~s}$

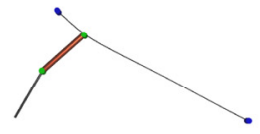

$t=0.4 \mathrm{~s}$

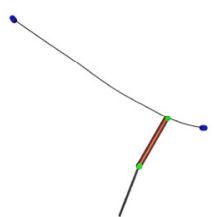

$t=0.9 \mathrm{~s}$

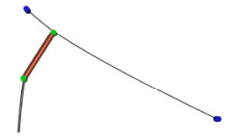

$t=0.5 \mathrm{~s}$

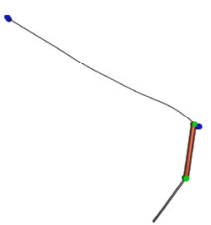

$t=1.0 \mathrm{~s}$

Fig.5 Motion of double pendulum subjected to sliding joint

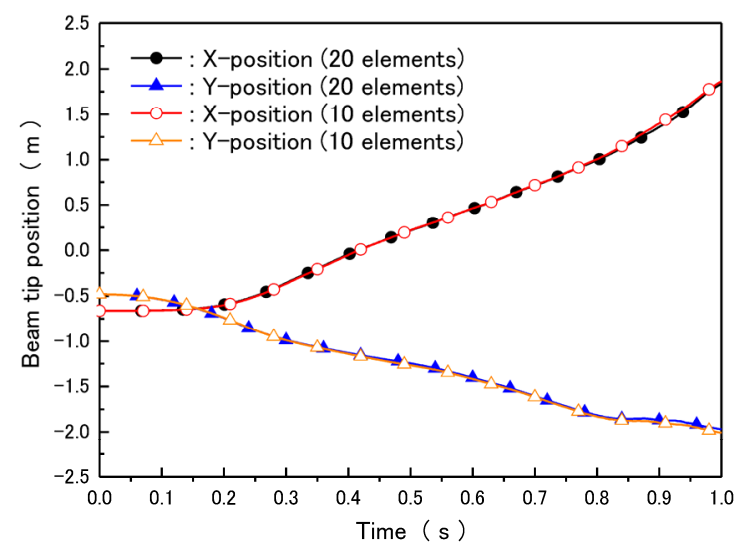

Fig.6 Beam tip position

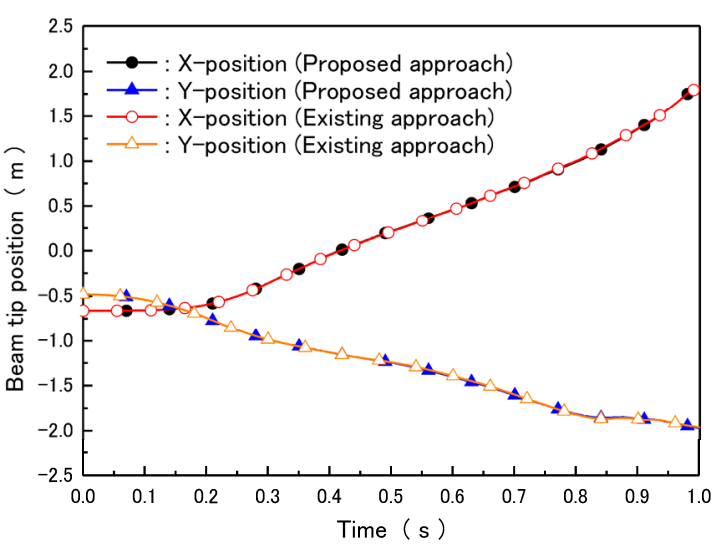

Fig.7 Comparison with existing approach (20elements) 
は 30 度傾いた長さ $2.0 \mathrm{~m}$ の弾性ケーブルとスライディングジョイントにより結合されており, 第 2 リンクに弾性 体を有する 2 重振子が弾性ケーブルに沿って滑り降りる運動を考える. ここで, いずれの弾性体も Absolute nodal coordinate formulation でモデルする. また，ケーブル，剛体リンクおよび弾性リンクの質量はそれぞれ $1.0 \mathrm{~kg}, 0.5 \mathrm{~kg}$ および $1.5 \mathrm{~kg}$ と仮定し，弾性体の軸および曲げ剛性はいずれも $E A=2.51 \times 10^{4} \mathrm{~N}$ および $E I=2.51 \mathrm{Nm}^{2}$ とした．ま た, 振子の大変位運動を許容寸るため, スライディングジョイントの拘束定義点では相対回転が拘束されないモ デル（ボールジョイント）を用いた，図 5 に運動の様子を示す. 本図より．２重振子が弾性ケーブルを滑り降り ていく運動が提案手法により計算できていることが分かる. 図 6 に弾性リンク先端の $X$ および $Y$ 変位を示す $(Z$ 変位は全てゼロ).弾性ケーブルの要素数が 10 および 20 とした場合, 結果に良い一致が見られることから, 10 要素でほぼ収束解を得ていることが分かる. また， 20 要素モデルに対して，中間座標を用いない既存の方法(2) 比較した結果を図 7 に示寸. 本図より両者に良い一致が見られ, 提案手法により剛体と弾性体間のスライディン グジョイント拘束が正しくモデル化できていることが分かる.

\section{$6 \cdot 2$ 大変形体を含む 4 節リンク (RSSR)機構}

式(20)で示したように，提案する中間座標を用いた定式化では，拘束定義点が固定された場合，回転ジョイン 卜を含む各種ジョイント拘束のモデル化にも適用可能であることを示寸，そこで，図 8 に示すように，クランク とフォロワーを剛体，カプラーを大変形弾性体としてモデル化した 4 節リンク(RSSR)機構を考える. モデルの諸 元は文献(6) と同じ值を用い, クランクには時間に依存した駆動卜ルクを与える. 各時刻における変形形状を図 9 に示し, 要素数を変化させた場合のカプラー中心位置の時間変化を図 10 に示す. なお, 弾性カプラーの要素分割 数を 20 とした場合, 系の自由度は 3 次元モデルを用いているため 236 である. 本図より, 大変形を伴う運動に 対してほぼ 20 要素で収束解を得ており, 提案手法により, 剛体と大変形を伴う弾性体が連成した柔軟マルチボデ イシステムのジョイント拘束が正しくモデル化できていることが分かる.

\section{7. 結言}

本論文では, Absolute nodal coordinate formulation でモデル化された大変形を伴う弾性体に対するシステマティ ックなスライディングジョイント拘束の定式化手法および計算アルゴリズムを提案した。提案手法では, 中間座

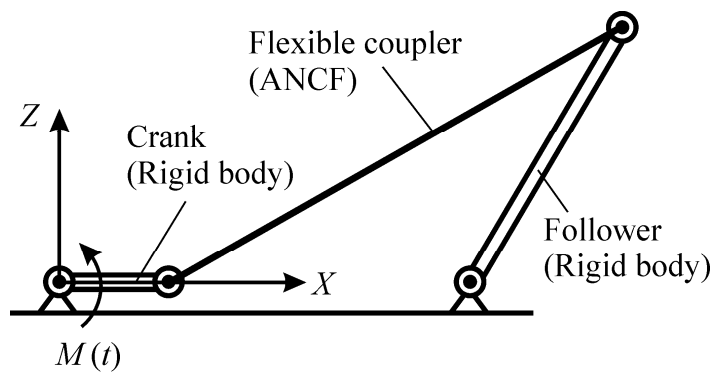

Fig.8 Four-bar mechanism
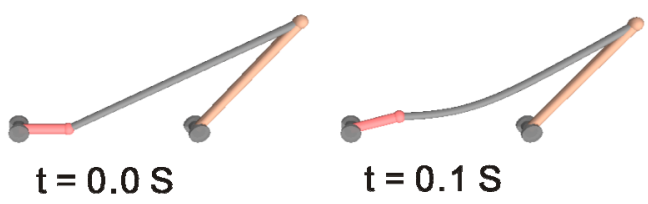

$\mathrm{t}=0.1 \mathrm{~S}$

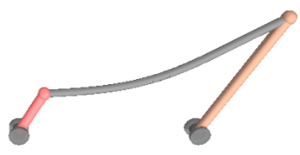

$\mathrm{t}=0.2 \mathrm{~S}$

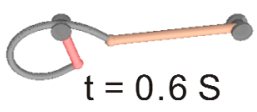

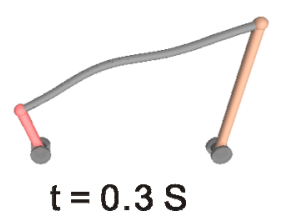

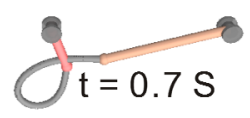

Fig.9 Motion of flexible four-bar mechanism 


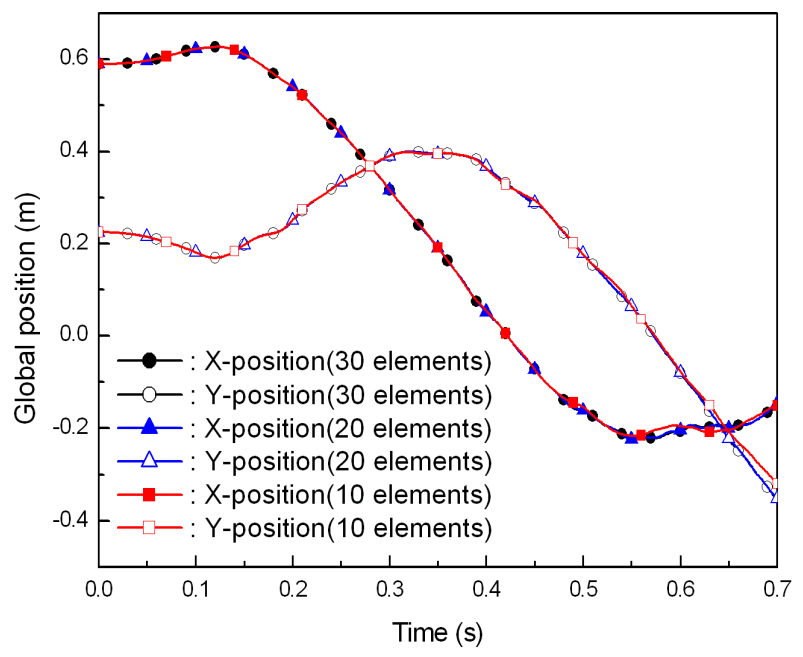

Fig.10 Global position of middle point on flexible coupler

標の概念をスライディングジョイント拘束に導入することで，既存のジョイント拘束ライブラリをそのまま利用 して，柔軟多体系に対寸るスライディングジョイント拘束を簡便に定式化できることを示した．さらに，スライ ディングジョイントに対する弧長変数および中間座標なるスラック変数を運動方程式中からシステマティックに 消去するアルゴリズムを提案し，既存の汎用マルチボディダイナミクスコードに Absolute nodal coordinate formulation でモデル化された弾性体のスライディングジョイント拘束を効率的に実装可能であることを示した.

\section{謝 辞}

本シミュレーションにご協力いただきました東京理科大学工学部機械工学科 4 年本多亮君に感謝の意を表します.

\section{文献}

(1) Shabana, A. A., Dynamics of Multibody Systems (2005), Cambridge University Press.

(2) Sugiyama, H., Escalona, J. L. and Shabana, A. A., "Formulation of Three-Dimensional Joint Constraints Using the Absolute Nodal Coordinates", Nonlinear Dynamics, Vol. 31 (2003), pp. 167-195.

(3) Sugiyama, H. and Yamashita, H., "Spatial Joint Constraints for the Absolute Nodal Coordinate Formulation using the Non-Generalized Intermediate Coordinates", Multibody System Dynamics, Vol. 26 (2011), pp. 15-36.

(4) Sugiyama, H., Gerstmayr, J. and Shabana, A. A., "Deformation Modes in the Finite Element Absolute Nodal Coordinate Formulation", Journal of Sound and Vibration, Vol.298 (2006), pp. 1129-1149.

(5) Shabana, A. A. and Sany, J. R., "An Augmented Formulation for Mechanical Systems with Non-Generalized Coordinates: Application to Rigid Body Contact Problems", Nonlinear Dynamics, Vol. 24 (2001), pp. 183-204.

(6) Berzeri, M., Campanelli, M. and Shabana, A. A., "Definition of the Elastic Forces in the Finite-Element Absolute Nodal Coordinate Formulation and the Floating Frame of Reference Formulation", Multibody System Dynamics, Vol. 5 (2001), pp. $21-54$. 